\title{
Estudo sociolinguístico da concordância verbal de 3 a pessoa do plural no português de São Tomé e Príncipe
}

\author{
Sociolinguistic study on third person plural verbal agreement \\ in São Tomé \& Príncipe's portuguese
}

Silvia Rodrigues Vieira1, Karen Cristina da Silva²

Professora associada (nível II) da UFRJ, Bolsista de produtividade do CNPq e Pesquisadora FAPERJ. E-mail: silviavieira@hotmail.com

Mestranda em Letras Vernáculas (U
RESUM0: Com o objetivo de verificar a existência de uma regra variável na concordância verbal de terceira pessoa do plural no Português de São Tomé e Príncipe, consoante a Teoria da Variação e Mudança, este estudo investiga as motivações linguísticas e extralinguísticas que atuam sobre o fenômeno. Partindo do princípio da heterogeneidade ordenada, foi feita a análise multivariada dos dados coletados de entrevistas sociolinguísticas do corpus VAPOR. Os resultados obtidos pelo programa computacional GOLDVARB-X foram interpretados à luz de hipóteses previamente levantadas, com especial atenção aos fatores relacionados ao multilinguismo, fortemente presente na região. Em correlação com outras variedades do Português, os resultados mostram tendências de preferência expressiva pela concordância, sugerindo adoção do modelo europeu. No entanto, os índices obtidos aproximam-se daqueles encontrados em trabalhos sobre a variedade urbana brasileira, o que permite a constatação de uma regra variável na variedade são-tomense. Além disso, observou-se a forte atuação dos fatores extralinguísticos sobre o fenômeno, fato que indica mais semelhanças com a variedade brasileira e pode, futuramente, trazer hipóteses sobre as situações de multilinguismo e a relação deste com a simplificação da morfologia verbal.

Palavras-chave: Concordância Verbal; Teoria da Variação e Mudança; Variedades do Português; Sociolinguística.

ABSTRACT: In order to verify the existence of a variable rule in the verbal agreement of third person plural in Portuguese of Sao Tome and Principe, according to the Theory of Variation and Change, this study investigates the linguistic and extralinguistic factors that act on the phenomenon. Considering the principles of orderly heterogeneity, it was made multivariate analysis of data, collected from sociolinguistic interviews of the corpus VAPOR. The results obtained by the computer program GOLDVARB-X were interpreted in the light of previously raised hypothesis, giving specia attention to some factors related to multilingualism that is strongly present in the region. In correlation with other varieties of Portuguese, the results show a significant preference for agreement marks, suggesting adoption of the European model. However, the rates obtained are similar to those found in studies on urban varieties of Brazilian Portuguese, which enables the establishment of a variable rule in the variety of Sao Tome. In addition, it was observed a strong actuation of extralinguistic factors on the phenomenon, which indicates more similarities with the Brazilian variety and which may bring hypotheses about the situations of multilingualism and its relationship with the simplification of verbal morphology in the future.

KEYwords: Verbal Agreement; Theory of Variation and Change; Portuguese Varieties; Sociolinguistics. 


\section{Introdução}

número reduzido de estudos no âmbito da concordância verbal em variedades africanas do Português e a importância da descrição dessas variedades para o debate relacionado à coexistência de normas na Língua Portuguesa justificam por si sós a realização do presente estudo. Em se tratando do tema da concordância, maior relevância se atribui à referida descrição pelo fato de que os dados africanos, dada a intensa situação de contato linguístico que caracteriza o continente em questão, podem, sem dúvida, trazer luzes à interpretação das origens do Português do Brasil.

O objetivo principal deste trabalho - que se integra aos estudos da concordância no âmbito do Projeto Estudo comparado dos padrões de concordância em variedades africanas, brasileiras e europeias do Português (Projeto ALFAL 21) - é verificar, consoante o aporte da Teoria da Variação e Mudança (WEINREICH, LABOV, HERZOG, 1968; LABOV, 1972, 1994, 2003), se a concordância verbal constitui uma regra variável no Português de São Tomé (PST) e, nesse caso, investigar as motivações linguísticas e extralinguísticas que favorecem ou desfavorecem a realização da marca de terceira pessoa do plural nas formas verbais. Em termos extralinguísticos, interessa especialmente examinar a influência da(s) língua(s) de intercomunicação utilizada(s) pelos informantes - dada a realidade de multilinguismo na região - sobre os resultados obtidos.

Assim sendo, o presente texto está organizado da seguinte forma: após esta introdução, descrevem-se brevemente as tendências relativas ao fenômeno em variedades do Português (Seção 2); apresentam-se os aspectos teórico-metodológicos variacionistas adotados na investigação (Seção 3); para, ao fim, expor os resultados obtidos com a análise do "corpus" (Seção 4) e tecer as considerações finais.

\section{Concordância e delimitação das variedades do Português}

As investigações sociolinguísticas acerca do fenômeno da concordância em amostras de fala brasileira, constituídas desde aproximadamente 1970, apresentaram evidências suficientes da produtiva variabilidade da regra no chamado Português do Brasil (PB). Essa variabilidade, entretanto, não se efetiva da mesma forma em todas as comunidades, especialmente se considerados fatores como a distribuição dos informantes quanto ao eixo rural-urbano, ao nível socioeconômico e, ainda, à escolaridade.

Tomando por base tão-somente três grupos de falantes oriundos da realidade linguística do Estado do Rio de Janeiro - representando a fala de indivíduos com curso superior, como os das amostras NURC-RJ (GRACIOSA, 1991) e Concordância ${ }^{1}$ (VIEIRA, 2011; BRANDÃO; VIEIRA, 2012a; VIEIRA; BAZENGA, 2013, 2015), com escolaridade fundamental/média, como os das amostras PEUL-RJ (SCHERRE, NARO, 1997, 2006) e Concordância (VIEIRA, 2011; BRANDÃO; VIEIRA, 2012a; VIEIRA; BAZENGA, 2013, 2015), e sem escolaridade, como os das amostras MOBRAL (NARO, 1981) e APERJ (VIEIRA, 1995) -, já se pode conceber o que Lucchesi; Baxter; Silva (2009) postularam como um continuum da variação no caso do PB. Esse continuum brasileiro revelaria o que o autor considera uma situação de polarização sociolinguística, o que pode ser representado no esquema a seguir, que contém não só os índices percentuais apresentados nos referidos estudos, mas também os do próprio trabalho de Lucchesi; Baxter; Silva (2009), com dados de comunidades rurais afrobrasileiras do interior da Bahia:

Para maiores detalhes, consultar <www.concordancia.letras.ufri.br $>$. 
Esquema 1 - Continuum de marcação de plural em verbos de $3^{\text {a }}$ pessoa em variedades brasileiras com base na proposta de Lucchesi; Baxter; Silva (2009, p. 348)

\begin{tabular}{|c|c|c|c|c|}
\hline $94 \%-97,8 \%$ & $73 \%-89 \%$ & $48 \%$ & $38 \%$ & $16 \%$ \\
\hline $\begin{array}{l}\text { Altamente } \\
\text { escolarizados da } \\
\text { cidade do Rio de } \\
\text { Janeiro } \\
\text { (GRACIOSA, 1991; } \\
\text { VIEIRA; BAZENGA, } \\
\text { 2013) }\end{array}$ & $\begin{array}{l}\text { Medianamente } \\
\text { escolarizados da } \\
\text { cidade do Rio de } \\
\text { Janeiro } \\
\text { (SCHERRE; NARO } \\
\text { 1997, 2006; } \\
\text { VIEIRA, 2011; } \\
\text { BRANDÃO; VIEIRA, } \\
\text { 2012a, 2012b; } \\
\text { VIEIRA; BAZENGA, } \\
\text { 2013; 2015) }\end{array}$ & $\begin{array}{l}\text { Analfabetos da } \\
\text { cidade do Rio de } \\
\text { Janeiro } \\
\text { (NARO, 1981) }\end{array}$ & $\begin{array}{l}\text { Pescadores } \\
\text { analfabetos do } \\
\text { interior do RJ } \\
\text { (VIEIRA, 1995) }\end{array}$ & $\begin{array}{l}\text { Analfabetos do } \\
\text { interior da Bahia } \\
\text { (LUCCHESI; } \\
\text { BAXTER; SILVA, } \\
\text { 2009) }\end{array}$ \\
\hline
\end{tabular}

Observando os extremos do continuum representado no Esq. 1, verificase a mencionada polarização, visto exibir, inversamente, muito alta e muito baixa realização da marca de número em verbos de 3 a pessoa plural ${ }^{2}$. Em primeiro lugar, é preciso cautela em qualquer tentativa de generalização desses resultados, tendo em vista não só a heterogeneidade das amostras em questão ${ }^{3}$, mas também o fato de que se consideram aqui apenas percentuais das realizações das marcas de plural. Como se sabe, percentuais não refletem mudanças em curso nem variação estável; somente os pesos relativos poderiam nortear qualquer afirmação de tendências quanto aos processos em curso na variedade brasileira. A proposta de Lucchesi; Baxter; Silva (2009), que inspirou a construção do Esquema 1, baseia-se, entretanto, na sistematicidade da correlação dos índices percentuais ao perfil das amostras

2 Estudos com dados recentes (NARO; SCHERRE, 1991; BRANDÃO; VIEIRA, 2012a, VIEIRA; BAZENGA, 2013,2015 ) têm apontado a tendência ao aumento geral das marcas de pluralidade, especialmente nos centros urbanos, o que se associa ao maciço processo de urbanização por que passou o Brasil e, ainda, ao aumento do acesso de todas as classes sociais às escolas.

3 ao aumento do acesso de todas as classes sociais às escolas.
3 Importante ressaltar as diferenças entre as amostras utilizadas em cada estudo referido no continuum, sobretudo quanto à época da constituição da amostra. Tais diferenças não inviabilizaram, entretanto, a representação das preferências por escolaridade e região (mais rural ou mais urbana), que ficam evidentes nos índices que constituem a base da proposta. quanto à escolaridade e ao perfil da comunidade, se mais rural ou mais urbana.

Tendo em vista que diversos estudos confirmam essas tendências relativas aos diferentes espaços diatópicos e diastráticos brasileiros, toma-se por hipótese que essa variabilidade se relacionaria, em algum grau, à história de constituição da nação brasileira com intensa situação de contato entre índios, negros e brancos. As feições linguísticas do PB derivariam do que Lucchesi; Baxter; Silva (2009) conceberam como um caso de transmissão linguística irregular, segundo a qual os modelos linguísticos adquiridos por novas gerações revelariam as adaptações típicas de situações de contato, dentre as quais se destaca a simplificação morfológica.

Situação absolutamente distinta é a que se revela em dados do Português Europeu. Embora não se disponha de grande número de estudos sobre essa variedade do Português, trabalhos recentes (MONGUILHOTT, 2010; VIEIRA, 2011; BRANDÃO; VIEIRA, 2012a, 2012b; MONTE, 2013; VIEIRA; BAZENGA, 2013; 2015) apontam alta produtividade da marca de número na fala de diversos estratos sociais, incluindo a de indivíduos sem escolaridade, com índices que vão de 91\% a 99,2\% de marcas de plural. Esses resultados, consideradas as diferenças nos critérios de coleta de dados, sugerem, conforme detalham Brandão, Vieira (2012a) e Vieira; Bazenga (2013; 2015), uma regra semicategórica de concordância nos termos de Labov (2003), cujos índices variam de 95 a 99\% e cuja qualidade dos dados também seria de natureza muito específica.

Por todo o exposto, interessa verificar se o padrão de concordância em variedades africanas do Português, que apresenta intensa situação de contato linguístico em certa medida semelhante à ocorrida no âmbito da constituição do Português do Brasil, se aproxima dos resultados brasileiros e/ou dos portugueses e em que aspectos. Na realidade específica do Português de São Tomé, a comparabilidade dos resultados pode ser ainda mais efetiva, visto se 
tratar, na amostra em estudo, de Português como língua materna, conforme declaração dos informantes, o que não se costuma verificar na maioria das variedades africanas, em que a Língua Portuguesa funciona usualmente como L2.

Consoante o Princípio do Uniformitarismo (cf. LABOV, 19724), evidências do presente podem sinalizar tendências relativas ao comportamento dos dados do passado. Por meio da observação dos processos em curso, esse princípio sustenta as bases da interpretação de resultados para a reconstrução histórica em vários trabalhos variacionistas. É nesse sentido que estudar as variedades africanas deve estar na agenda das pesquisas sociolinguísticas sobre a concordância: guardadas as devidas particularidades na formação do PB e das variedades africanas do Português, análises contrastivas diversas e desenvolvidas em amostras estratificadas segundo os mesmos critérios permitirão observar as semelhanças e diferenças linguísticas nesse processo de constituição de determinado padrão linguístico.

\section{0 tratamento dos dados: aspectos teórico-metodológicos}

Para a análise de dados, a investigação adota, como pressuposto geral, o princípio da heterogeneidade ordenada (WEINREICH, LABOV, HERZOG, 1968), segundo o qual as variantes - formas alternantes com mesmo valor referencial empregadas no mesmo contexto por indivíduos da mesma comunidade de fala - ocorrem consoante a atuação de restrições linguísticas e extralinguísticas.

Cumprindo as etapas necessárias à realização de uma análise multivariada a partir do pacote de programas Goldvarb-X, foram realizados os seguintes procedimentos: (i) coleta de dados; (ii) codificação dos dados segundo

${ }^{4}$ Esse princípio teve como seu precursor, na Linguística, William Dwight Whitney (1867 apud Labov 1994). variáveis preestabelecidas; (iii) execução das rodadas segundo o Goldvarb-X; (iv) interpretação dos resultados quantitativos à luz das hipóteses (sócio) linguísticas formuladas previamente.

No que se refere à coleta de dados, o trabalho vale-se de 27 entrevistas da amostra santomense que integra o Corpus VAPOR (cf. www.clul.ul.pt), amostra coletada em 2009 pelo investigador Tjerk Hagemeijer, ${ }^{5}$ da Universidade de Lisboa, e cedida ao já referido Projeto Estudo comparado dos padrões de concordância em variedades africanas, brasileiras e europeias do Português (Projeto ALFAL 21). Trata-se de todos os informantes que se declaram falantes de Português como L1 e cujo perfil se encaixa na estratificação das variáveis sociais propostas para a pesquisa. Assim, os informantes foram distribuídos em (i) faixa etária: A (18-35 anos), B (36-55 anos) e C (37-75 anos); (ii) escolaridade: nível 1 (ensino fundamental), nível 2 (ensino médio) e nível 3 (ensino superior); e (iii) sexo ${ }^{6}$.

Além dessas variáveis referentes à constituição da amostra, o estudo também investigou a influência da(s) língua(s) de intercomunicação utilizada(s) pelo informante, de acordo com o grupo de fatores idealizado por Brandão (2011), em estudo da concordância nominal na fala dos 5 A respeito da situação multilinguística em São Tomé e Príncipe, recomenda-se a consulta a Hagemeijer
(2009).

6 Em Vieira; Bazenga $(2013 ; 2015)$, os resultados da pesquisa - desenvolvida no âmbito do referido Projeto - referem-se apenas aos 17 informantes que permitiam a análise comparativa com os resultados do Português do Brasil e do Português Europeu, ou seja, controlam um homem e uma mulher de cada faixa etária e cada nível de escolaridade, o que geraria um total de 18 informantes. Não foi possível entretanto, considerar uma informante idosa de curso superior, porque a amostra VAPOR não apresenta qualquer gravação com esse perfil, motivo pelo qual se chega ao total ímpar de informantes (17 e não 18). No presente trabalho, além desses 17 entrevistados, o estudo acrescenta os dados de uma amostra de 10 informantes jovens em fase escolar, cursando do $6^{\circ}$ ao $11^{\circ}$ ano (totalizando 27 entrevistados). São informantes na faixa etária de 10 a 19 anos, sendo 5 meninas e 5 meninos. Acredita-se que o acréscimo desses possa permitir a observação mais ampla do fenômeno em tempo aparente. Embora se tenha consciência do desejável respeito à premissa básica da estratificaç̃o da amostra julgou-se se tenha consciência do desejavel respeito a premissa básica da estratificação da amostra, julgou-se viável esse procedimento tendo em vista que resultados de estudos anteriores (BRANDAO; VIEIRA, $2012 \mathrm{a}, 2012 \mathrm{~b}$ ) demonstraram que ambas as subamostras, controladas separadamente, apresentaram as mesmas tendências. Ademais, foi relevante contar com maior número de ocorrências e, ainda, maior
variabilidade de contextos estruturais. 
informantes da mesma amostra. Nesse grupo de fatores, controla-se, com base nos próprios depoimentos dos informantes, o uso que fazem das línguas crioulas locais na comunicação diária, de modo a verificar se eles utilizam apenas o Português; o Português e, eventualmente, um crioulo; ou, ainda, um crioulo em casa e o Português nas situações fora de casa. Conforme declaram Brandão; Vieira (2012b, p. 12),

(...) em São Tomé, características de seu processo de povoamento deram ensejo a que se formasse uma sociedade de caráter multilíngue, que optou por instituir o Português como única língua oficial depois de se ter tornado independente de Portugal em 1975. Segundo Hagemeijer (2009), além do Português, em São Tomé são faladas duas línguas crioulas autóctones - o Santomé ou Forro e o Angolar - com elas coexistindo, ainda, o crioulo de Cabo Verde, o Lung'ie, da ilha do Príncipe, o Português dos Tongas, e resquícios de línguas do grupo Banto. Nesse conjunto, destacam-se o Português e o Santomé, que, de acordo com dados de censo realizado em 2001, são usados, respectivamente, por $98,9 \%$ e $72,4 \%$ da população com mais de cinco anos (p. $1 ; 18)$, que, em geral, domina duas ou mais das línguas mencionadas.

Além dos grupos de fatores de natureza extralinguística, foram controladas variáveis de natureza estrutural, algumas delas consideradas relevantes em outras investigações, quais sejam: posição do sujeito em relação ao verbo, distância entre o núcleo do SN e o verbo, presença de elementos intervenientes, configuração morfossintática do sujeito, número de constituintes do sujeito, paralelismo no nível oracional (do sujeito para o verbo), animacidade do referente sujeito, saliência fônica, tempo/modo verbal e transitividade verbal.

Por fim, aplicou-se o pacote de programas Goldvarb X, que gerou os números para análise e interpretação dos resultados. Consoante a realização de oito rodadas multivariadas (mediante combinações diversas de fatores, exclusão de variáveis, dentre outros procedimentos), as variáveis que se mostraram relevantes foram, nesta ordem, escolaridade, animacidade do referente sujeito, posição do sujeito, sexo e paralelismo oracional.

\section{Análise dos resultados: a marcação em verbos de $3^{\text {a }}$ pessoa plural no PST}

Como resultado geral, verificou-se, consoante Labov (2003), a atuação de uma regra variável com forte preferência pela concordância padrão, uma vez que, dentre os 1053 dados coletados, apenas 100 apresentaram ausência da marca de 3 a pessoa plural. Dessa forma, os 953 dados de marcação de 3 a pessoa plural representam $90,5 \%$ de concordância, como pode ser verificado na Tabela 1.

Tabela 1 - Distribuição dos dados com e sem marca verbal de $3^{a}$ pessoa plural no Português de São Tomé (PST)

\begin{tabular}{lcc}
\hline Marca Verbak & \% & Ocorrências \\
Marcação de plural & 90,5 & $953 / 1053$ \\
Não-marcação de plural & 9,5 & $100 / 1053$ \\
\hline
\end{tabular}

\subsection{Restrições extralinguísticas}

Detalhando os resultados, a escolaridade - primeira variável selecionada em todas as rodadas - mostra-se bastante relevante no condicionamento do fenômeno nos dados do Português de São Tomé, como é possível verificar na Tabela 2 e no Gráfico 1.

Tabela 2 - Atuação da variável Escolaridade para a marcação de $3^{\text {a }}$ pessoa plural no PST

\begin{tabular}{lccc}
\hline Escolaridade & V. Absoluto & $\%$ & Peso Relativo \\
Fundamental & $290 / 348$ & 83 & .25 \\
Médio & $371 / 406$ & 91 & .48 \\
Superior & $292 / 299$ & 98 & .82 \\
Total & $953 / 1053$ & 90,5 & - \\
\hline
\end{tabular}


Gráfico 1 - Atuação da variável Escolaridade para a marcação de $3^{\text {a }}$ pessoa plural no PST (pesos relativos)

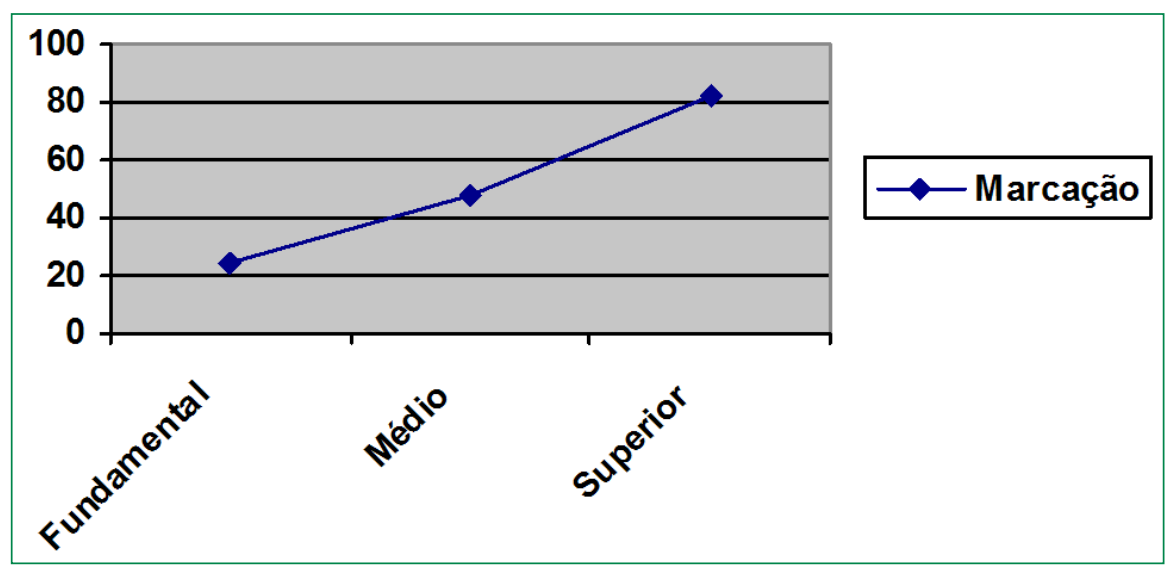

Nota-se que os informantes de alta escolaridade apresentam forte preferência pela concordância (.82), ao contrário do que acontece com os informantes de baixa escolaridade, os de nível fundamental, que se mostram desfavorecedores da marcação de plural (.25). Os informantes de ensino médio manifestam, por sua vez, comportamento neutro em relação ao condicionamento do fenômeno.

De modo geral, pode-se afirmar que as mesmas tendências relativas ao grau de instrução dos informantes que foram verificadas no Esq. 1, representando a variedade brasileira, acontecem na amostra são-tomense em análise, ressalvando que esta apresenta apenas informantes da cidade (e não da área rural). Vieira; Bazenga $(2013,2015)$, em estudo comparando exclusivamente os informantes de mesmo perfil, demonstram que os falantes de nível fundamental de escolaridade de São Tomé apresentam concordância similar aos falantes de ensino médio do português brasileiro. Sendo assim, pode-se propor que o status do Português de São Tomé, de língua de alto prestígio social, pode favorecer maior realização da marca plural como um todo, o que, sem dúvida, precisa ser confirmado em outros estudos do fenômeno e no maior detalhamento da análise.

A variável escolaridade mostra-se tão influente na sociedade sãotomense que apresenta íntima relação com a utilização da própria Língua Portuguesa e/ou de outras línguas na intercomunicação diária. Para compreender melhor essa interação, cabe observar os resultados relativos ao cruzamento dos dois grupos de fatores, expostos na Tab. $\mathbf{3}$.

Tabela 3 - Distribuição dos dados de marcação de 3aa pessoa plural no PST consoante o cruzamento das variáveis Escolaridade e Língua de intercomunicação

\begin{tabular}{lcccccc}
\hline \multirow{2}{*}{$\begin{array}{l}\text { Escolaridade } \times \text { Língua de } \\
\text { Intercomunicação }\end{array}$} & \multicolumn{2}{c}{ Fundamental } & \multicolumn{2}{c}{ Médio } & \multicolumn{2}{c}{ Superior } \\
\cline { 2 - 3 } & Freq. & $\%$ & Freq. & $\%$ & Freq. & $\%$ \\
Só Português & $91 / 105$ & 87 & $178 / 195$ & 91 & $138 / 142$ & 97 \\
$\begin{array}{l}\text { Português; eventualmente, } \\
\text { crioulo }\end{array}$ & $128 / 154$ & 83 & $193 / 211$ & 91 & $154 / 157$ & 98 \\
$\begin{array}{l}\text { Crioulo em casa; fora, } \\
\begin{array}{l}\text { Português } \\
\text { Total }\end{array}\end{array}$ & $71 / 89$ & 80 & $0 / 0$ & 0 & $0 / 0$ & 0 \\
\hline
\end{tabular}

Os falantes com menor escolaridade, os de nível fundamental, exibem os níveis mais baixos de marcação de pluralidade nos verbos, principalmente aqueles que declaram falar o Crioulo em casa e, fora de casa, o Português $(80 \%)$. Situação bastante diversa é a dos informantes com média e alta escolaridade. Estes, além de apresentarem os mais altos índices de marcação (que atinge $98 \%$ na fala dos indivíduos com curso superior), declaram usar exclusivamente o Português ou eventualmente um crioulo, motivo pelo qual não se registram, na Tab. 3, ocorrências produzidas por indivíduos com média e alta escolaridade no que se refere ao fator "Crioulo em casa; 
fora, Português". Os resultados do cruzamento evidenciam que, na amostra em análise, quanto maior a escolaridade, maior o contato com a Língua Portuguesa, o que, por sua vez, acarreta maior realização da marca de pluralidade.

Valendo-se da proposta de Labov (2003) - que propõe a categorização de regras em categóricas (100\% de uma das formas), semicategóricas ( 95 a 99\% de uma das formas) e variáveis (5-95\% de uma das formas) -, observa-se que os universitários apresentam cerca de 98\% de concordância, enquadrando-se na classificação de uma regra semicategórica. Os falantes de ensino médio e fundamental apresentam variação, com evidente diferença entre eles. É importante destacar que o cruzamento com a variável "língua de intercomunicação" se mostra importante para a compreensão desse quadro: os falantes de ensino fundamental que usam o crioulo em casa são os que mais apresentam ausência de concordância, exatamente ao usarem o Português, fora de casa.

Quanto à variável sexo, vemos a confirmação da hipótese laboviana de que as mulheres, em situação de mudança acima do nível de consciência, favorecem variantes de prestígio. Sendo a marcação de plural uma variante de alto prestígio social e sinalizador do domínio da Língua Portuguesa por parte dos falantes de São Tomé, as mulheres apresentam maiores índices de marcação plural (.64), se comparados aos referentes à fala dos homens (.40).

Tabela 4 - Atuação da variável Sexo para a marcação de 3로 pessoa plural no PST

\begin{tabular}{lccc}
\hline Sexo & V. Absoluto & $\%$ & Peso Relativo \\
Homem & $508 / 579$ & 88 & .40 \\
Mulher & $445 / 474$ & 94 & .64 \\
Total & $953 / 1053$ & 90,5 & - \\
\hline
\end{tabular}

Letrônica | Porto Alegre, v. 10, n. 1, p. 18-29, jan.-jun. 2017

\subsection{Restrições linguísticas}

Considerando as variáveis linguísticas, destaca-se a atuação do traço semântico do referente sujeito, se animado (exemplo 1) ou inanimado (exemplo 2).

(1) “as pessoas me olhavam com bons olhos" (PSTA3H)

(2) "e depois eu com essas dificuldades todas, mesmo assim, as dificuldades não acaba". (PSTA2H)

Essa variável ${ }^{7}$ confirma os resultados previamente esperados, uma vez que sujeitos com traço + animado favorecem a concordância (.57), enquanto os sujeitos com traço -animado a desfavorecem (.22).

Tabela 5 - Atuação da variável Animacidade do sujeito para a marcação de $3^{\underline{a}}$ pessoa plural no PST

\begin{tabular}{lccc}
\hline \multicolumn{1}{r}{ Animacidade } & V. Absoluto & \% & Peso Relativo \\
+ animado & $816 / 879$ & 93 & .57 \\
- animado & $137 / 174$ & 79 & .22 \\
Total & $953 / 1053$ & 90,5 & - \\
\hline
\end{tabular}

A variável posição do sujeito ${ }^{8}$ também confirma a tendência esperada, a de que sujeitos antepostos favorecem a concordância, enquanto os pospostos a desfavorecem.

7 Vieira; Bazenga (2015, p. 72-73) apresentam reflexões a respeito da universalidade da atuação da variável referente ao traço semântico do sujeito.

${ }^{8}$ Não se consideraram os dados de sujeito não expresso no controle dos grupos de fatores "Posição do sujeito em relação ao verbo" e "paralelismo oracional", motivo pelo qual o total de dados em análise é menor nesses casos. Esse procedimento metodológico justifica-se pela própria razão de ser dessas variáveis: a expressão do sujeito é condição fundamental para que se avalie a influência da presença do sintagma nominal e suas marcas sobre a marcação de pluralidade no verbo. 
Tabela 6 - Atuação da variável Posição do sujeito para a marcação de 3 a pessoa plural no PST

\begin{tabular}{lccc}
\hline Posição do Sujeito & V. Absoluto & $\%$ & Peso Relativo \\
\hline Anteposto & $633 / 688$ & 92 & .54 \\
Posposto & $38 / 53$ & 72 & .14 \\
Total & $671 / 741$ & 91 & - \\
\hline
\end{tabular}

Em casos de sujeitos antepostos (exemplo 3), registrou-se índice favorecedor da marca de número (.54), quando comparado ao referente aos casos de sujeitos pospostos (exemplo 4), em que se registrou o desfavorecimento da concordância padrão (.14).

(3) "Espero que as coisas corram bem." (PSTB2M)

(4) "não é lulinha, morre aquelas lula grande mesmo". (PSTA1H)

A respeito dessa variável, é necessário observar sua correlação com o tipo de verbo em questão. Scherre; Naro; Cardoso (2007) discutem o papel do tipo de verbo na concordância verbal, fazendo uma análise minuciosa sobre a relação entre tipo de verbo e diversas outras variáveis implicadas no fenômeno em questão. Em linhas gerais, os autores demonstram que, de fato,

os verbos transitivos exibem predominantemente o argumento externo à sua esquerda; os verbos existenciais privilegiam um argumento único à sua direita; e os verbos impessoais só ocorrem com sintagmas à direita. Também não há dúvida de que, entre os casos de construções com sujeitos/sintagmas pospostos, há predominância de verbos intransitivos inacusativos, embora haja também muitas construções em que os inacusativos aparecem com argumento à esquerda do verbo. Entretanto, independentemente do tipo de verbo, qualquer argumento ou sintagma à direita do verbo tende, relativamente, a diminuir as marcas de concordância explícita (SCHERRE; NARO; CARDOSO, 2007, p. 312).
Desse modo, os autores sublinham a maior relevância da posição do sujeito para o condicionamento da concordância verbal. Ademais, apontam a necessidade de maior detalhamento no controle das características semânticas de cada tipo verbal, bem como dos papeis temáticos dos constituintes sentenciais. No que se refere às características do verbo, fica patente que é a saliência fônica - discutida adiante - o fator predominante no condicionamento do fenômeno.

Por fim, o paralelismo no nível oracional - que postula que marcas no SN sujeito levam a marcas no verbo (SCHERRE; NARO, 1993) - foi confirmado nos dados da fala santomense.

Tabela 7 - Atuação da variável Paralelismo no nível oracional para a marcação de $3^{\text {a }}$ pessoa plural no PST

\begin{tabular}{lccc}
\hline Paralelismo Oracional & V. Absoluto & \% & Peso Relativo \\
SN marcado & $625 / 672$ & 93 & .53 \\
SN não marcado & $17 / 29$ & 59 & .16 \\
Total & $642 / 701$ & 91,5 & - \\
\hline
\end{tabular}

De fato, SNs sem marca de plural (exemplo 5) desfavorecem a realização da marca de número no verbo (.16), ao passo que a presença da marca no SN (exemplo 6) a favorece (.53).

(5) "as condições financeira não permitia prosseguir" (PSTA1H)

(6) "Os meus filhos passavam no jardins" (PSTA1M)

Além das variáveis já descritas, a saliência fônica na oposição singularplural e a transitividade verbal merecem destaque, embora tenham demonstrado comportamento instável nas rodadas realizadas, sendo ora selecionadas pelo programa, ora não. Analisando mais detalhadamente os resultados, verificou-se uma sobreposição entre tais variáveis, de modo 
que, quando o grupo Saliência era selecionado, Transitividade não o era e vice-versa, apresentando, também, um comportamento por vezes diferente daquele que já é esperado e das hipóteses que já são conhecidas sobre essas variáveis.

A saliência fônica, que postula que a maior diferenciação fônica entre as formas verbais singular e plural favorece a marcação de plural (LEMLE; NARO, 1977), apresentou uma atuação mais forte nos extremos dos graus controlados. Foi possível verificar sua atuação no grau mais baixo de saliência, no qual só há mudança pelo acréscimo ou ausência de uma nasal, como no par deve/devem (Grau 1), e também no grau mais alto, em que ocorre uma mudança completa ou quase completa das formas verbais, como em é/são, veio/vieram (Grau 5) ${ }^{9}$.

A transitividade, quando selecionada, mostrou a referida interface com a saliência fônica, deixando evidente que os níveis mais baixos de saliência ocorrem com os verbos inergativos (existe/existem), inacusativos (morre/morrem) e copulativos (era/eram). Nesse sentido, tanto boa parte dessas construções verbais quanto o baixo nível de saliência, em conjunto, favoreceriam a não-marcação de pluralidade.

Para aprofundar essa interação, foi feito um cruzamento entre os grupos de fatores que pode ser visualizado no Gráfico 2, adiante.

Por meio da observação do Gráfico 2, fica evidente a sobreposição entre as variáveis saliência fônica e transitividade verbal. Primeiramente, nota-se que apenas no grau 1 há a presença de todos os tipos verbais. Ademais, pode-se perceber que a maior presença da não-marcação associada aos verbos inacusativos, inergativos e copulativos se encontra nos níveis mais baixos de saliência, até o grau 3 basicamente. Nos altos níveis de saliência

9 Os fatores controlados e referidos no Graf. 3 apresentam graus crescentes de diferenciação das formas
singular e plural, que podem ser representados pelos seguintes pares: Grau 1 - pode/podem, canta/ cantam; Grau 2 - faz/fazem; Grau 3 - vai/vão; Grau 4 - falou/falaram; e Grau 5 - veio/vieram; é/são. fônica (graus 4 e 5), praticamente não se registraram dados dos referidos padrões de transitividade. Confirmou-se, assim, a referida relação entre os dois grupos de fatores, mencionada anteriormente. De modo geral, o Gráfico 2 reafirma a pertinência da saliência fônica, uma vez que os graus mais baixos (1 e 2) são os que mais favorecem a ausência de concordância e os mais altos (4 e 5) a favorecem.

Gráfico 2 - Distribuição percentual dos dados de marcação de 3aㅡ pessoa plural no PST consoante o cruzamento das variáveis Saliência fônica e Transitividade dos verbos

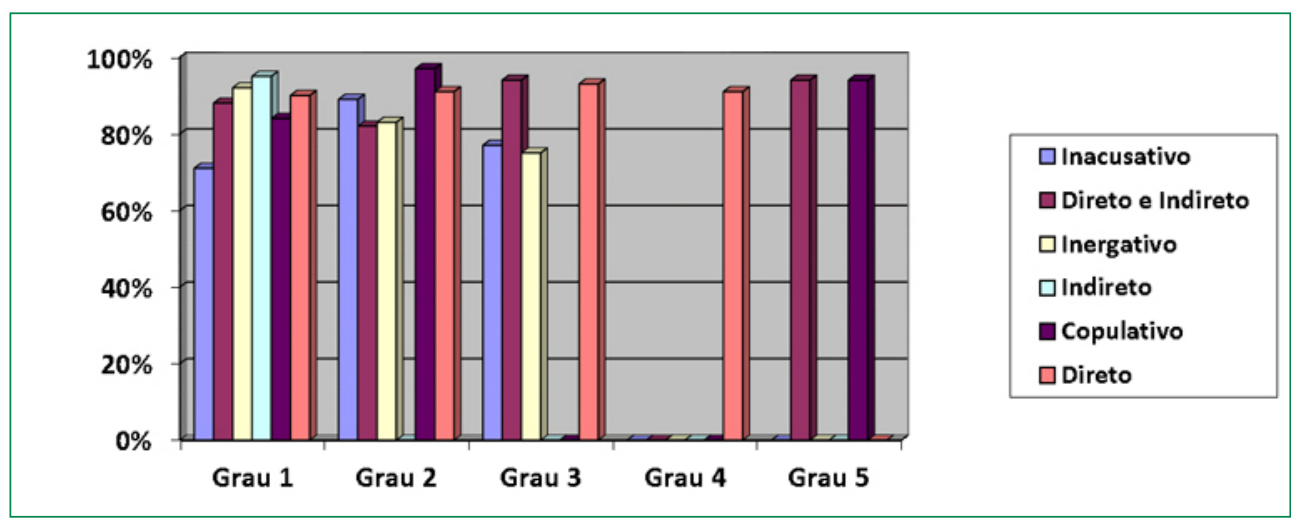

\section{Considerações finais}

Com base nos resultados obtidos na investigação, pode-se confirmar a configuração de uma regra variável, nos termos de Labov (2003), na variedade urbana do Português de São Tomé e Príncipe, com preferência expressiva pela concordância padrão, de forma ainda mais evidente do que a já atestada em Vieira; Bazenga (2013; 2015). De um lado, a produtividade das marcas verbais de plural sugere a adoção, ainda que parcial, do modelo europeu de 
concordância. Por outro lado, o índice obtido no PST é semelhante ao que se verifica no Português do Brasil em variedades urbanas com alto e mediano graus de escolaridade, conforme se demonstrou no Esq. 1, o que sinaliza o status do Português na sociedade são-tomense, que é de alto prestígio social. Em outras palavras, os padrões de concordância em PST urbano verificados no presente estudo não correspondem exatamente aos verificados para o $\mathrm{PE}$ (com dados semicategóricos em geral) - apesar de este ser o modelo que os são-tomenses supostamente tendem a seguir, por ser a prestigiosa variedade do colonizador -, mas também não chegam a se igualar aos das variedades brasileiras, sobretudo as populares, com índices mais baixos de realização da marca de pluralidade.

De modo geral, há que se ressaltar os aspectos coincidentes da concordância verbal no PB e no PST contemporâneos. Embora as situações de contato dessa variedade africana possam contemplar aspectos distintos da brasileira, que não convive atualmente com línguas crioulas ou africanas, as semelhanças podem apontar uma variação inerente do português não lusitano, independentemente das situações de comunicação locais. Assim, resultados como os apresentados no presente estudo podem fundamentar, em última instância, propostas como as de Petter $(2009,2015)$, da existência de um continuum afro-brasileiro nas variedades do Português.

As variáveis extralinguísticas que se mostraram relevantes ao favorecimento da ausência de concordância foram escolaridade e sexo, mostrando tendências de incremento da marca de concordância para os mais escolarizados e para as mulheres. Essa sensibilidade a fatores extralinguísticos também aproxima a variedade são-tomense e a brasileira. Além disso, o controle da variável referente à língua de intercomunicação dos falantes, que está diretamente relacionada à escolaridade, evidenciou que a menor escolaridade se correlaciona ao maior contato com línguas crioulas, o que resulta, em última instância, em menor concordância. Esse resultado - que também confirma os de Vieira; Bazenga (2013; 2015) - é de fundamental importância, por sugerir que situação equivalente possa ter acontecido na formação do Português do Brasil, em virtude das semelhanças no que se refere ao contato multilinguístico - no caso com línguas indígenas, africanas e portuguesa a um só tempo.

As variáveis linguísticas relevantes confirmaram tendências já amplamente verificadas no Português do Brasil; desse modo, a animacidade, a posição do sujeito e o paralelismo oracional demonstraram, respectivamente, maiores índices de marcação de plural com sujeitos animados, antepostos ao verbo e formalmente marcados. A análise detalhada das variáveis saliência fônica e transitividade demonstrou forte correlação entre elas, motivada, sobretudo, pela presença expressiva de dados de baixa diferenciação das formas singular e plural, especialmente em verbos dos padrões inergativo, inacusativo e copulativo. Desse modo, a presente análise apresenta um refinamento, em relação às pesquisas anteriores (BRANDÃO; VIEIRA, 2012a, 2012b; VIEIRA; BAZENGA, 2013, 2015), no sentido de aprofundar a correlação entre variáveis e, ainda, observar os dados da variedade são-tomense consoante a ampliação do número de dados.

Para aprofundar a análise ora apresentada, o prosseguimento da investigação deverá contar não só com a comparação dos resultados obtidos com os de outras variedades do Português, mas também com a busca de novas fontes para o estudo de variedades africanas em geral, a começar pela moçambicana (cujo corpus está em fase de construção), de modo a compreender melhor como esses indivíduos adquirem e repassam a Língua Portuguesa para novas gerações. Somente após o mapeamento do fenômeno nas diversas subamostras do Português recolhidas segundo os mesmos critérios de constituição, será possível discutir em maior profundidade o impacto das situações de intenso multilinguismo em relação ao grau de simplificação da morfologia verbal. 


\section{Referências}

BRANDÃO, Silvia F. O cancelamento da marca de número nominal na variedade urbana não standard do Português de São Tomé. Documentos del XVI Congreso Internacional de la ALFAL. Alcalá de Henares: ALFAL, 2011. CD-Rom.

BRANDÃO, Silvia F.; VIEIRA, Silvia R. Concordância nominal e verbal: contribuições para o debate sobre o estatuto da variação em três variedades urbanas do Português. Alfa, São Paulo, v. 56, n. 3, p. 1035-1064, 2012a.

BRANDÃO, Silvia F.; VIEIRA, Silvia R. Concordância nominal e verbal no Português do Brasil e no Português de São Tomé: uma abordagem sociolinguística. Papia, v. 22, n. 1, p. 7-40, 2012b.

GRACIOSA, Diva. Concordância verbal na fala culta carioca. Dissertação (Mestrado em Letras Vernáculas) - Universidade Federal do Rio de Janeiro, Rio de Janeiro, 1991.

HAGEMEIJER, Tjerk. As línguas de São Tomé e Príncipe. Revista de Crioulos de Base Lexical Portuguesa e Espanhola, v. 1, n. 1, p. 1-27, 2009.

LABOV, William. Sociolinguistic patterns. Philadelphia: University of Pennsylvania Press, 1972.

LABOV, William. Principles of linguistic change. v. 1. Oxford, Cambridge: Blackwell, 1994.

LABOV, William. Some sociolinguistic principles. In: PAULSTON, Christina B.; TUCKER, G. Richard (Org.). Sociolinguistics. The essential readings. Oxford/New York: B. Blackwell, 2003. p. 234-250.

LEMLE, Miriam; NARO, Anthony J. Competências básicas do Português. Rio de Janeiro: Fundação Movimento Brasileiro de Alfabetização, 1977.

LUCCHESI, Dante; BAXTER, Alan; SILVA, Jorge A. A. da. A concordância verbal. In: LUCCHESI, Dante; BAXTER, Alan; RIBEIRO, Ilza (Org.). O Português afro-brasileiro. Salvador: Edufba, 2009. p. 331-371.

LUCCHESI, Dante; BAXTER, Alan; RIBEIRO, Ilza (Org.) O Português afro-brasileiro. Salvador: Edufba, 2009.

MONGUILHOTT, Isabel. Estudo sincrônico e diacrônico da concordância verbal de $3^{\underline{a}}$ pessoa do plural no PB e no PE. Tese (Doutorado em Linguística) - Universidade Federal de Santa Catarina, Florianópolis, 2009.
MONTE, Alexandre. Concordância verbal e variação: um estudo descritivo-comparativo do Português Brasileiro e do Português Europeu. Tese (Doutorado em Linguística e Língua Portuguesa) - Universidade do Estado de São Paulo, Araraquara, SP, 2012.

NARO, Anthony J. The social and structural dimensions of a syntactic change. Language, v. 57, n. 1, p. 63-98, 1981. https://doi.org/10.1353/lan.1981.0020

NARO, Anthony J.; SCHERRE, Maria Marta P. Variação e mudança linguística: fluxos e contrafluxos na comunidade de fala. In: SILVA, Omena M. de O. e; TARALLO, Fernando. (Org.). Cadernos de Estudos Linguísticos, Campinas, UNICAMP/IEL, v. 20, p. 9-16. 1991.

PETTER, Margarida M. T. Aspectos morfossintáticos comuns ao português angolano, brasileiro e moçambicano. Papia, v. 19, p. 201-220, 2009.

PETTER, Margarida M. T. Ampliando o continuum afro-brasileiro de Português. Papia, V. 25 , n. 2 , p. $305-317,2015$.

SCHERRE, M. M. P.; NARO, A. J. Duas dimensões do paralelismo verbal no Português popular do Brasil. DELTA, v. 9, n. 1, p. 1-14, 1993.

SCHERRE, Maria Marta P.; NARO, Anthony J. A concordância de número no Português do Brasil: um caso típico de variação inerente. HORA, Dermeval. (Org.). Diversidade linguística no Brasil. João Pessoa: Ideia, 1997. p. 93-114.

SCHERRE, Maria Marta P.; NARO, Anthony J. Mudança sem mudança: a concordância de número no português brasileiro. SCRIPTA, v. 9, n. 18, p. 107-129, 2006.

SCHERRE, Maria Marta P.; NARO, Anthony J.; CARDOSO, Caroline R. O papel do tipo de verbo na concordância verbal no português brasileiro. DELTA, v, 23, n. esp., p. 238-317, 2007.

VIEIRA, Silvia R. Concordância verbal: variação em dialetos populares do Norte Fluminense. Dissertação (Mestrado em Letras Vernáculas) - Universidade Federal do Rio de Janeiro, Rio de Janeiro, 1995.

VIEIRA, Silvia R. O estatuto da regra variável e o fenômeno da concordância verbal em variedades do Português. Documentos del XVI Congreso Internacional de la ALFAL. Alcalá de Henares: ALFAL, 2011. CD-Rom.

VIEIRA, Silvia R.; BAZENGA, Aline. Patterns of third person verbal agreement. Journal of Portuguese Linguistics, v. 12, n. 2, p. 7-50, 2013. https://doi.org/10.5334/jpl.67 
VIEIRA, Silvia R.; BAZENGA, Aline. A concordância da terceira pessoa plural: padrões em variedades do Português. In: VIEIRA, Silvia R. (Org.). A concordância em variedades do Português: a interface Fonética-Morfossintaxe. Rio de Janeiro: Vermelho Marinho, 2015. p. 29-75.

WEINREICH, Uriel; LABOV, William; HERZOG, Marvin. Empirical foundations for theory of linguistic change. In: LEHMANN, Winfred; MALKIEL, Yakov (Org.). Directions for Historical Linguistics. Austin: University of Texas Press, 1968. p. 97-195.

Recebido em 18/08/2016

Aceito em 14/01/2017. 